\title{
Performance of Internet of Things (IoT) Potential Applications in Education
}

\author{
Tanjea Ane \\ Lecturer \\ Department of Computer Science \& Information Technology \\ Bangabandhu Sheikh Mujibur Rahman Agricultural University, Gazipur-1706, Bangladesh \\ E-mail: tanjea@bsmrau.edu.bd \\ Masum Billah \\ Assistant Professor \\ Department of Computer Science \& Information Technology \\ Bangabandhu Sheikh Mujibur Rahman Agricultural University, Gazipur-1706, Bangladesh \\ E-mail: masumb06@bsmrau.edu.bd \\ Tabatshum Nepa \\ Lecturer \\ Department of Politics and Governance \\ Gono Bishwabidyalay, Savar, Dhaka-1344, Bangladesh \\ E-mail: niipa.ju35@gmail.com
}

Received: April 29, 2020

Accepted: May 30, 2020

Online Published: July I0, 2020

doi: I0.4628I/bjmsr.v2i2.653

URL: https://doi.org/I0.4628I/bjmsr.v2i2.653

\begin{abstract}
Internet of Things (IoT) very fast growing interaction that has connected real and virtual objects anytime, anywhere though network. A variety of various connected objects influence the applications of education process which is like a new change with research opportunities and possibilities. In education ecosystem IoT emerges as rapidly dynamic technology for the improvement of traditional education system. This paper consists of five parts: firstly an overview of IoT use, secondly IoT application in education system, thirdly recent survey IoT work then discusses Io $\mathrm{T}$ impacts in the higher education and concludes the paper.
\end{abstract}

Keywords: IoT, Smart Education, Smart Classroom, Future Learning.

\section{Introduction}

Cloud computing is an intelligent computing technology and distributed application, over the internet many users can get access data centers that is available for the user. Internet connectivity has increased for being part of IoT and the most crucial part of IoT is cloud computing applications are made on the demand of mobility and extended networking, the cloud is important part for IoT's applications. Example: Now days we feel the need working with big data, cloud is helpful to store data and other interrelated companies can easily access the data for processing through IoT. IoT generates lots of data on the other hand, cloud computing paves way for this data to make easier to access for end user. Cloud computing and internet of things are working to increase the efficiency of everyday task. Io $T$ will be totally reliant on the cloud computing, can assist IoT for a very large-scale application. There are many technologies that enable the IoT in both wired and wireless communication technology. For short range communication Bluetooth, ZigBee, Wi-Fi etc. technology is used. VSAT technology is available for long range communication and wired communication Ethernet, PLC have more usability (Farooq, Waseem, Mazhar, Khairi, \& Kamal, 2015).

Technology companies (ARRIS, CableLabs, Cisco, Electrolux, GE Digital, Intel, Microsoft, Qualcomm and Samsung) have started working with the Internet of Things (IoT). Another paper (Miraz, Ali, Excell, \& Picking, 2015), reviewed IoT, IoE (Internet of Everything) and IoNT (Internet of Nano Things). Both CISCO and Qualcomm have analyzed the meaning and showed their technical scenario in paper. Four layers e.g., people, data, process and things are discussed for future expansion for Internet of things that enriches the internet activity incorporating machine-to-machine, person-to-machine and person-to-person systems. IoE is being implemented with IoNT incorporating nano-sensors this provides access to data from remote places that 
was nearly impossible to be detected, supporting the advanced processing and better clarification. As IoT includes Big data analysis and have created more reliant technology on which our daily applications are dependent. Internet services may face newly challenges and hence online platform requires safety to protect analyzed data in global environment. Paper (Riahi, Natalizio, Challal, Mitton, \& Iera, 20I4) referred the 'The Internet of Things (IoT)' is an active participant and where people interact in a technological ecosystem. IoT is complex paradigm including complex processing system and parallelly connecting global things in presence of critical threats. Paper discussed the interactions among four IoT components: intelligent object, technological ecosystem, person as well as process and mentioned how to protect the third-party attack in the large dimension of critical issues in the purpose to make a security system for IoT.

How would be future internet architecture, possible applications and challenges are discussed in paper (Khan, Khan, Zaheer, \& Khan, 2012). Present internet communications between human to human but next internet is going towards machine to machine communication. (Ray, 2018) Internet of Things used to refer things is becoming smarter; processing becomes more intelligent and provides smart solution. Internet of Things (IoT) makes a strong connection with digital world where a number of networks are working together simultaneously. Internet of Things architectures is discussed in this survey paper also showed the data exchange formats, data encoding, and addressing schemes of packets for data communication. It surveyed IoT cloud solution is capable of analyzing real time data and managing the central server from remote distance. Social Internet of Things (SIoT) platform for newly social connection is proposed here.

Internet of Everything (IoE) tells the benefits of connecting people, process, data, and things (Mitchell, Villa, Stewart-Weeks, \& Lange, 2013). IoT and IoE are related and their relationship is drawn according to working principle and smart things becoming smarter and it highlighted Internet of Things (IoT) and the wider IoE. Both are getting efficiency for not only data transfer but also getting better secured communication policy. A distributed architecture is discussed, where data can be applied in real time at the edge of the network, as well as in batch-mode in the cloud ensures better computing capability and data analysis.

(Sundmaeker, Guillemin, Friess, \& Woelfflé, 2010) reviewed few key drivers having great impact at Internet of Things e.g., energy, intelligence, communication, integration, interoperability. In order to clear identification system there is a demand to have a technically sound solution than can guarantee to make a strong privacy and user will get secured data communication over worldwide internet. (Huang \& Li, 20I0) showed the internet applications and their similarity model and why their services are comparable with traditional model. The properties of world based new internet with attributes are shown here including the three properties of product information e.g., electronic tag form, standardizing restraint as well as ontology supporting. (Chen et al., 20I I) Described a common fabric for integrating IoT with cloud computing. For upcoming future internet generation, it will be more suitable platform for sensing and data communication technology also provides a possible solution of privacy protection mechanism. Only the Internet of Things (IoT) can change us with existing system. Now, IoT is everyday networking like in our education, communication, business, science, government, agriculture and humanity. Io $T$ becomes very essential part for our education ecosystem and IoT is presenting future education with high quality for gathering, analyzing and distributing knowledge.

\section{IoT Application in Education Ecosystem 2.I Smart Teaching}

Traditional teaching approach that has come to end with smart education system. Education system is being replaced 'chalk-talk' method by new technological devices (Finger Touch, Pen Based, Teaching Pointer etc.). IoT education refers as 'seven daystwenty four hours teaching center' for interested learners. As shown in the figure I below smart teaching is about the objects, classrooms are connected with technology. In higher education students need an environment where they will have diversity of knowledge, study space, research opportunities, internet availability in lab. IoT creates an adaptable learning area to help them knowledge sharing from each other.

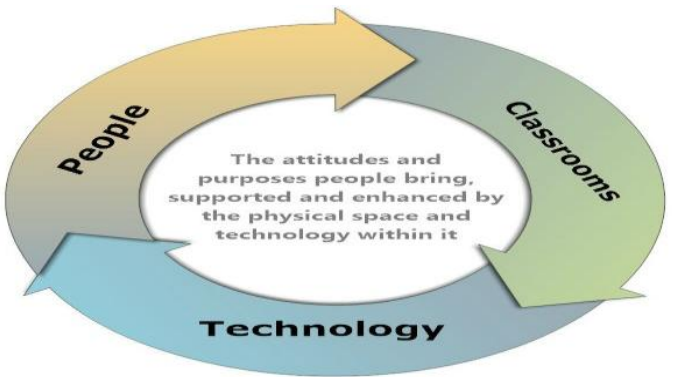

SMART Teaching

Figure I. Smart Teaching

Source: Smart Teaching (2015) 
Moreover, IoT offers novel electronic teaching and learning area while objects teach other objects creating electronic groups in collaboration with teachers and students. Quality of education strongly has been made sure for education platforms. In addition, education ecosystem is networking among virtual physical objects with smart technology.

\subsection{Smart Learning}

Educational experts appraise smart learning as self-education in order to encouraging the learners to work besides their textbooks contents. This motivates learners in independent research work without formal analog education steps. Student gets answers from online source. They are not waiting for others assistance to step out in research experiments. Anytime, anything from anywhere research resources are available that they need to work. In IoT lab interacts with objects, sensors, data bandwidth and connects component with cloud computing, it makes faster learning. Now learners can monitor and observe their lab experimental actions within real time by using smart monitoring technology devices i.e. indoor camera, smart voice controller, tracking devices, Bluetooth tracking sensors, smart alert clock. Smart learning environments pave the way to adapt learners to take information and processing it as digital learning formats.

\subsection{Smart Classroom}

Smart classroom is a place of learning, teaching and assessment happens in an intellectual environment. Education activities are involved differently but still in effective and interactive way, used as useful and beneficial for both faculty and students. Smart classroom makes the teaching learning system easier way that provides better classroom management. Teacher and students may know what is the objective and purpose of education in technological based way in smart classroom management system. Teachers take actions according to the students' performance. They take up possible decisions for improvement the quality of higher education performance. Smart technological tools i.e. document camera, interactive whiteboard, interactive projector, simple projector, digital camera; graphic tablets are being used in smart classroom. As shown in the figure 2 below smart classroom concept is about the wired and wireless medium are connected with technology.

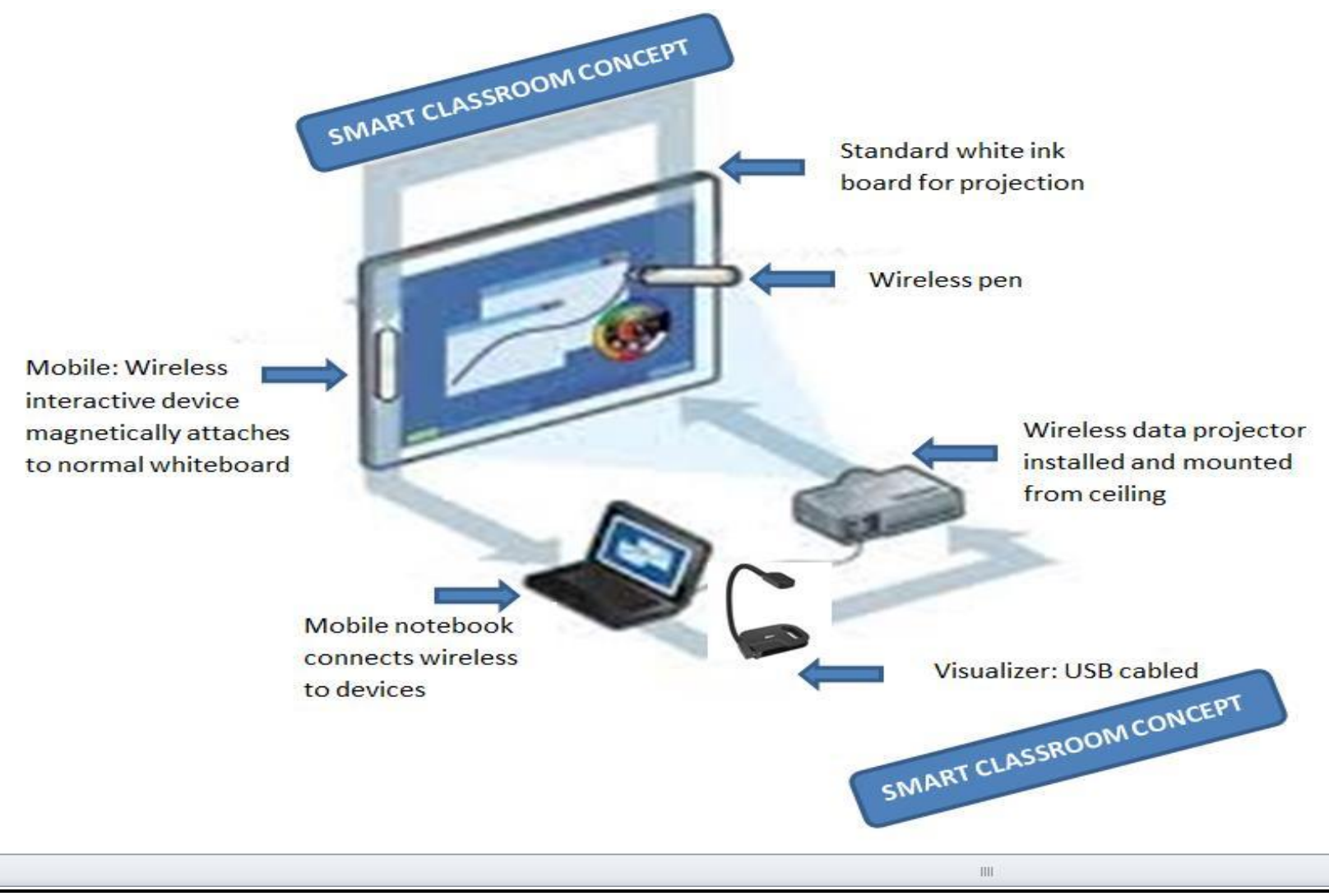

Figure 2. Smart classroom View

Source: Smart Classroom (2015) 
Most of recent studies show smart classroom concept for smart education which can be useful to enrich teaching, learning and assessment processes.

\section{Recent work of IoT in Education \\ 3.I Green Io T Impact}

Virtual, smart classroom benefit the learners in divisive way. Previous study tools are replaced and scale up by smart devices. The aim of G-IoT (Green-Internet of Things): IoT applications in education are being extended. It supports engineering education learning platform. Engineering education formerly was class-content oriented design, students work on lab passed full day, these lab experiments were online based but used just for information and was very difficult to implement. G-IoT at engineering education now connected classroom, lab with students via technology. Students are allowed to perform the lab experiment reactions from anywhere. Open source projects, online training are available which brings them real world experiences. Future education is enduring problem solving knowledge sharing education system that guarantees improved teaching, learning quality and supported by IoT vision (Maksimovic, 2017). Figure 3 presents future education for 2030.

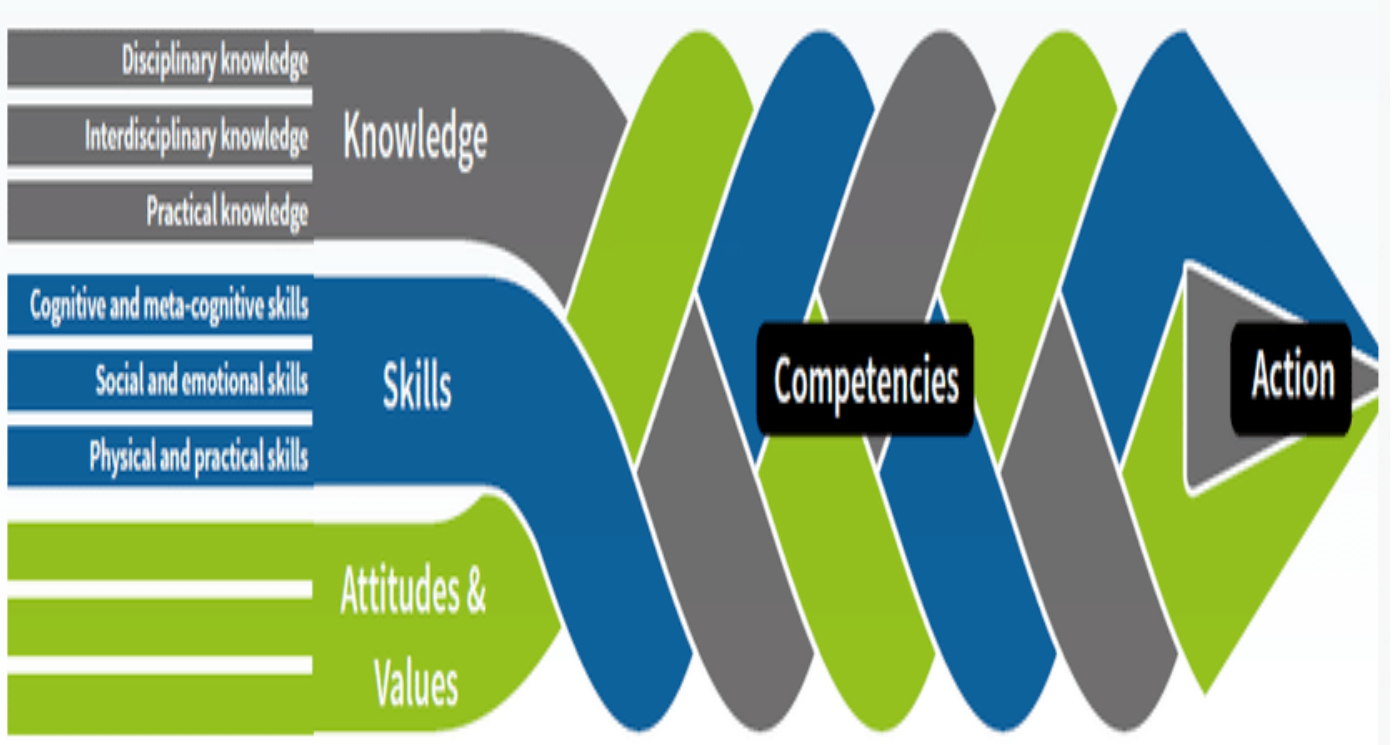

Figure 3. Technology vision for future education for 2030 Source: Future Education Skill (2018)

With help of IoT and G-IoT the vision of education ensures a sustainable education system. It provides the ICT resources sustainability with greener behavior of teachers, students and staff. G-IoT leads optimal resources utilization, ICT equipment's reuse, increase of G-IoT practice, decreases expenditure in education.

\subsection{IoT in Higher Education Ecosystem Impact}

A result of questionnaire based statistical report was revealed, data were collected for the survey from university students and teachers (Abbasy, 2017). Teacher perception result shows, they are satisfying with IoT application in education. About (80 to 90) percentage of instructors are agree that IoT has a great influence at learning is shown in figure 4 while figure 5 depicts the perception of students view. Some cases from student perception view, they agree with instructors in three cases i.e. e-learning, research and hyper connectivity. From statistical graphical perception view results are varied less in few criteria and highly match in particularly three parameters. So teachers and student have trust on IoT technology in education system that proved IoT has implied great factors in education ecosystem. 


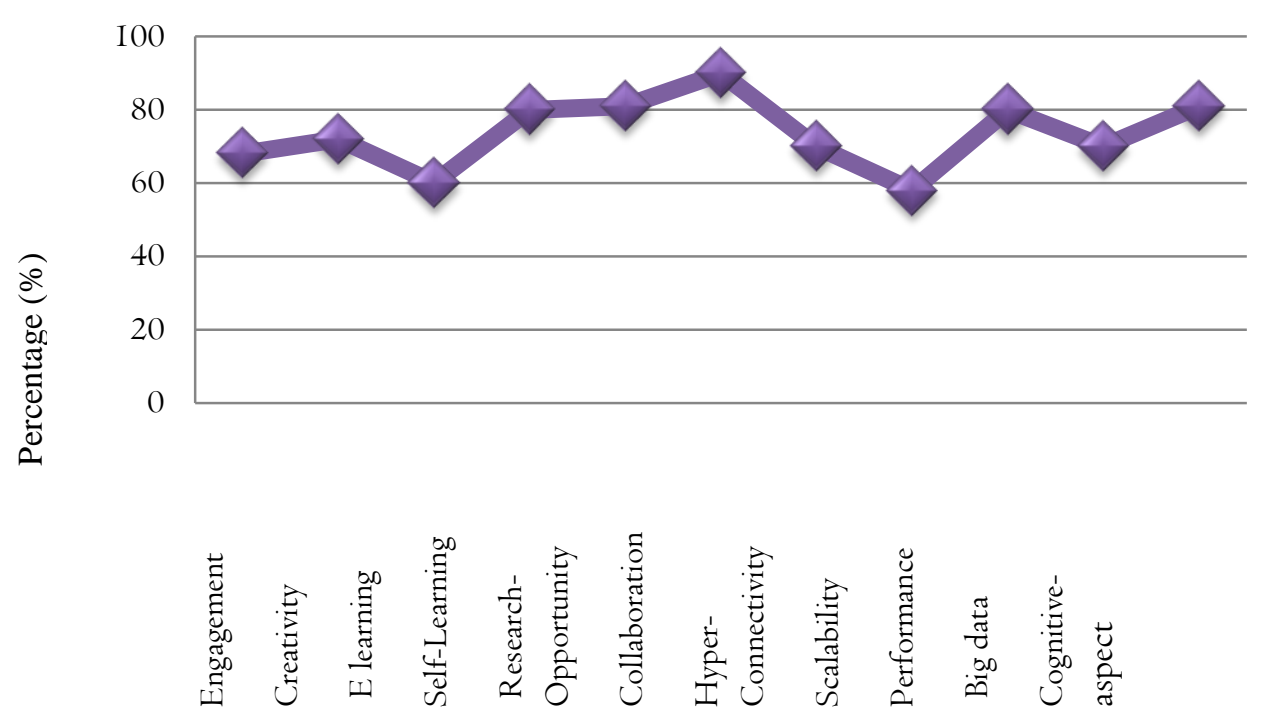

Figure 4. Teacher Perception Result

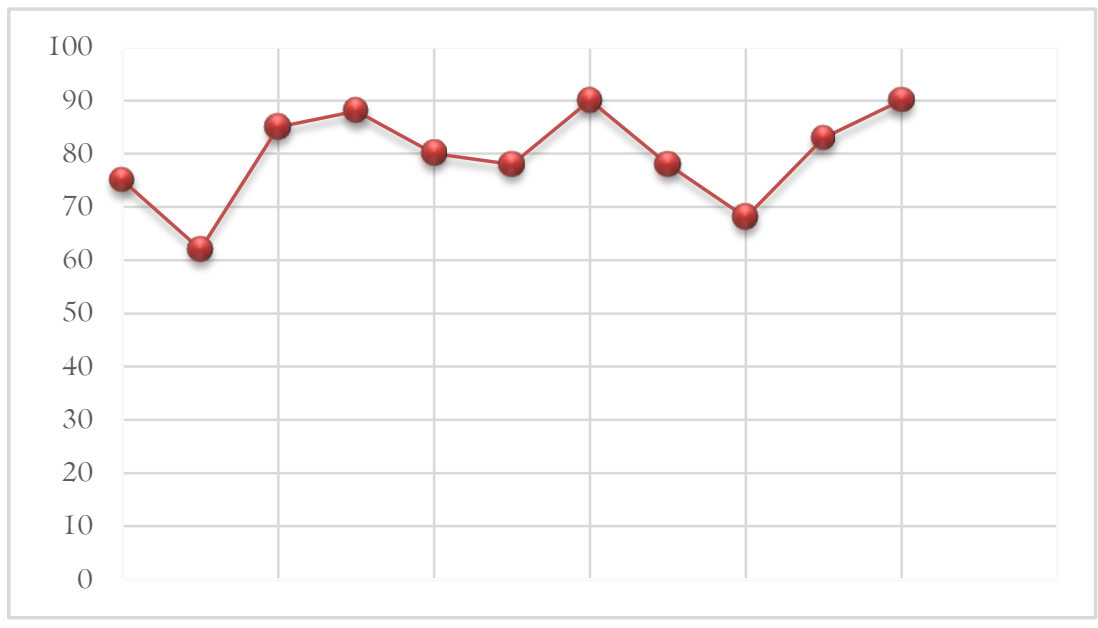

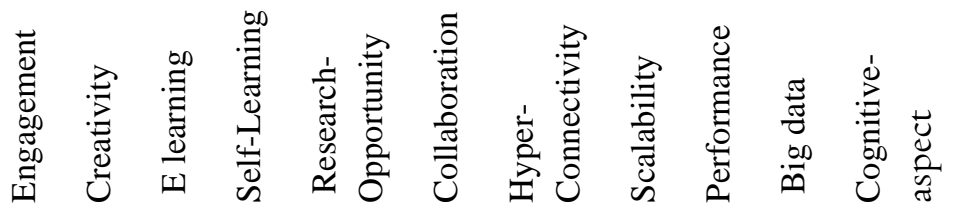

Figure 5. Student Perception Result

\section{IoT in Higher Education}

There is a prediction IoT directly and indirectly will affect teaching and learning process in future. IoT broadly affects teachinglearning system to upgrade the quality of education so that in more appealing and quantifiable environment teacher will perform 
the duties to fulfill the variant needs of students. This paper takes three aspects to be improved: teaching, learning and assessment.

\section{I Improve Learning Efficiency}

In higher education system their needs individual stakeholders for better management. Various devices are connected in IoT communications to help learning process in efficiently that reduces individualized management and will lead rapid and better progress of higher learning experiences.

\subsection{Mobile Learning Applications}

IoT is strongly connected network with smart mobile technology.Students can keep a track of audios/videos to help themselves in study on mobile storage as needed. Teachers can provide assignment task on mobile used applications and at anytime both can login mobile system then take a review of progressive report. Mobile technology can be accessed at anytime from anywhere. Use of IoT with smart mobile system will be a new massive chance for better higher learning approaches.

\subsection{Research Computing and Opportunity}

IoT continues to confirm its benefits for research work in higher education, it will make big data available so that faculty of universities and students may increase interdisciplinary research by analyzing big data in high quality computing platform. To upgrade system IoT will put sensor, audio/video smart technology, distributed network that will link up researchers in online wireless medium to share knowledge based dialogue in faster process both for input and output. IoT technology will provide huge possibilities among the research learners in higher education.

\section{Conclusion}

This paper shows the possible progress in higher education with the advancement IoT i.e. Internet of Things. Io $\mathrm{T}$ system has many challenges while moving traditional teaching, learning process to smart one system that positively affects entire teachinglearning and assessment process in higher education. Higher education will have a tremendous success that increase learning speed. Based on reality, our future work will highlight how the existing IoT implementations make sustainable education ecosystem in higher teaching learning process.

\section{References}

Abbasy, M. B., \& Quesada, E. V. (2017). Predictable influence of IoT (Internet of Things) in the higher education. International Journal of Information and Education Technology, 7(I2), 9I4-920.

Chen, C. Y., Chao, H. C., Wu, T. Y., Fan, C. I., Chen, J. L., Chen, Y. S., \& Hsu, J. M. (20I I). IoT-IMS communication platform for future internet. International Journal of Adaptive, Resilient and Autonomic Systems (IJARAS), 2(4), 74-94.

Farooq, M. U., Waseem, M., Mazhar, S., Khairi, A., \& Kamal, T. (20I5). A review on internet of things (IoT). International Journal of Computer Applications, II3(I), I-7.

Future Education Skill. (2018). Retrieved from https://www.researchgate.net/figure/The-Future-of-Education-and-SkillsOECD-Education-2030-Framework-Knowledge-skills_fig7_3260320I0

Huang, Y., \& Li, G. (2010, May). A semantic analysis for internet of things. In 2010 International Conference on Intelligent Computation Technology and Automation (Vol. I, pp. 336-339). IEEE.

Khan, R., Khan, S. U., Zaheer, R., \& Khan, S. (2012, December). Future internet: the internet of things architecture, possible applications and key challenges. In 2012 IOth international conference on frontiers of information technology (pp. 257-260). IEEE.

Miraz, M. H., Ali, M., Excell, P. S., \& Picking, R. (2015, September). A review on Internet of Things (IoT), Internet of everything (IoE) and Internet of nano things (IoNT). In 2015 Internet Technologies and Applications (ITA) (pp. 219-224). IEEE.

Maksimovic, M. (2017). Green Internet of Things (G-IoT) at engineering education institution: the classroom of tomorrow. Green Internet of Things, 270-273.

Mitchell, S., Villa, N., Stewart-Weeks, M., \& Lange, A. (2013). The internet of everything for cities. Connecting People, Process, Data, and Things to Improve the 'Livability'of Cities and Communities, Cisco.

Riahi, A., Natalizio, E., Challal, Y., Mitton, N., \& Iera, A. (20I4, February). A systemic and cognitive approach for IoT security. In 2014 International conference on computing, networking and communications (ICNC) (pp. I83-I88). IEEE.

Ray, P. P. (2018). A survey on internet of things architectures. J King of Saud Univ Comput Inf Sci. 
Sundmaeker, H., Guillemin, P., Friess, P., \& Woelfflé, S. (2010). Vision and challenges for realising the Internet of Things. Cluster of European Research Projects on the Internet of Things, European Commision, 3(3), 34-36.

Smart Teaching. (20I5). Retrieved from https://edtechnology.co.uk/Blog/new-classrooms-smart-teaching/

Smart Classroom. (20I5). Retrieved from http://edulis.pgwc.gov.za/index.php/smart-classroom/e-learning/smart-classrooms

\section{Copyrights}

Copyright for this article is retained by the author(s), with first publication rights granted to the journal. This is an open-access article distributed under the terms and conditions of the Creative Commons Attribution license (http://creativecommons.org/licenses/by/4.0/). 